\title{
A mulher militar no Brasil no século XXI: uma análise com base nos sete indicadores propostos por Helena Carreiras (2006)
}

\author{
The military woman in Brazil in the 21st century: an analysis based on the seven indicators proposed by \\ Helena Carreiras (2006)
}

DOI: https://doi.org/10.22456/2178-8839.113848

Isabella Neumann

Universidade Federal de Santa Catarina, Florianópolis, Brasil

isabellaneumannn@gmail.com

Graciela de Conti Pagliari Universidade Federal de Santa Catarina, Florianópolis, Brasil graciela.pagliari@gmail.com

\section{Resumo}

O objetivo deste artigo é realizar uma apreciação do estágio no qual se encontra a incorporação da mulher militar no Brasil na segunda década dos anos 2000, a partir de dados fornecidos pelos três comandos das Forças Armadas e do Ministério da Defesa. Partindo da compreensão que o sexo feminino nas Forças Armadas é um dos elementos que compõe as relações civis-militares, analisa-se, com base nos indicadores estabelecidos por Carreiras (2006), a i) a porcentagem da mulher no total da Força ativa; ii) a distribuição das mulheres militares em funções; iii) as restrições formais para funções de combate; iv) as restrições formais de categorias; v) a porcentagem de mulher na categoria de oficiais; vi) a segregação em treinamento básico; e vii) os programas para a integração de gênero. Ao fim, conclui-se que a mulher ainda não está satisfatoriamente integrada às Forças Armadas do Brasil, seja em termos quantitativos ou qualitativos, porque elas não ocupam, em sua totalidade, os cargos e funções das Forças Armadas.

Palavras-chave: Mulher Militar; Forças Armadas; Defesa;

\begin{abstract}
This article aims to achieve an appraisal of the stage in which the incorporation of the military woman in Brazil is found in the second decade of the 2000's, based on data provided by the three commands of the Armed Forces and the Ministry of Defense. We start from the understanding that the female sex in the Armed Forces is one of the elements that make up civil-military relations and we analyze, based on the indicators established by Carreiras (2006), the i) percentage of women in the total active force; ii) the distribution of military woman in functions iii) the formal restrictions on combat functions; iv) the formal category restrictions; v) the percentage of women in the category of officers; vi) the segre gation in basic training; and vii) the programs for gender mainstreaming. In the end, we concluded that women are not yet satisfactorily integrated into the Armed Forces of Brazil, either in quantitative or qualitative terms, because they do not occupy, in their entirety, the positions and functions of the Armed Forces.
\end{abstract}

Keywords: Military Women; Armed Forces; Defense;

Recebido: 09 maio 2021 Aceito: 20 agosto 2021 


\section{Introdução}

O período que compreende o fim do conflito bipolar de poder revelou aos estudiosos das Relações Internacionais que o Estado nacional, embora seja o ator primordial, não atua como o único influenciador das dinâmicas do sistema. Particularmente no caso da Segurança Internacional, as instituições e os indivíduos passaram a adquirir atenção não apenas como receptores, mas como agentes que importavam no desenvolvimento de um conflito. As Forças Armadas, por serem uma Instituição do Estado, também procederam com certas modificações em sua estrutura.

Uma significativa alteração nas Forças Armadas é retratada com a abertura da caserna às mulheres militares. No Brasil, a partir da década de 1980, e com maior peso a partir da década de 1990, passou -se a aceitar que o sexo feminino atuasse - de maneira não inaugural, mas inédita sob o aspecto formal - de seus Corpos. As explicações para essa abertura partem de uma conjunção de elementos que se estendem de demandas tanto externas como domésticas. Do ponto de vista internacional, respondeu bem às mudanças convocadas pela nova gestão da guerra e às demandas de Organizações Multilaterais, seja pela pró-igualdade de gênero ou pela contribuição nas operações de peacekeeping (SCHWETHER, 2016; MOORE, 2017). A respeito do viés doméstico, foi conveniente às pautas de gênero movimentadas pela população dos centros urbanos, à necessidade da mulher embuscar espaços produtivos fora de casa, à ocupação de cargos técnicos, à crise de recrutamento militar e ao maior contato entre a sociedade e as Forças Armadas (MATHIAS; ADÃ O, 2013).

A questão é desenhada em Resoluções internacionais, como a 1325/200 do Conselho de Segurança da ONU, que informam como as mulheres contribuem na eficácia das operações. Os proveitos são vários, desde obter melhor pessoal qualificado (porque deixa-se de desconsiderar 50\% do potencial de uma população); lograr uma ampla coleta e análise de informações, em razão da legitimidade que aquela Força passa a dispor; e alcançar uma mais acessível compreensão das condições e cultura locais (GIANNINI; LIMA; PEREIRA, 2016). Notadamente nas operações de paz e humanitárias, a introdução da perspectiva de gênero é essencial devidoàs tarefas que circulam em âmbitos civis e militares, muitas vezes se sobrepondo. Nessas ocasiões, é particular interessante o papel feminino militar em reconduzir mulheres civis a uma qualidade de vida pós-conflito, seja através de mentoria, exemplo, aprendizagem, proteção contra a violência sexual e de gênero ou até pela oportunidade da comunicação, tendo em vista a possibilidade de el as serem censuradas, por vezes, de manterem contato com homens.

Para tanto, a presença da mulher militar nas Forças Armadas influencia no relacionamento civil -militar de um Estado porque o gênero se configura como uma arena onde as tensões do Estado, Forças Armadas e sociedade se desdobram (CARREIRAS, 2015). Burk (2002) manifesta a pertinência de submeter as relações civis -militares através de suas capacidades de, efetivamente, sustentarem e protegerem os valores democráticos, e, se julgadas como insatisfa tórias, cumprirem as adaptações necessárias. No mesmo viés, as autoras Penido e Mathias (2019) afirmam que é a comunidade civil aquela indispensável para a consecução dos valores, instituições e práticas de um Estado, de modo que os interesses nacionais sejam desenvolvidos por eles e não mediante a decisão de atores militares. Isto é, a participação da mulher militar nas Forças Armadas do Brasil tem a força de revelar se há ou não uma preferência militar que sobrepõe às demandas sociais pós-modernas e, nesta razão, pode apontar se a Instituição castrense está descolada da sociedade e se, ainda, mantém sua fidelidade com formas patriarcais e ultrapassadas cujo paradigma se associa a uma superioridade militar masculina, agressiva e desrespeitosa (CARREIRAS, 2015).

É nesse sentido, então, que o presente artigo realiza uma apreciação do estágio no qual se encontra a incorporação da mulher militar no Brasil na segunda década dos anos 2000, já que entende que a avaliação dessa participação opera como agente do grau de convergência entre as Forças Armadas e a sociedade. Aqui será empreendida uma análise da situação mulher militar no Brasil no século XXI com base em sete indicadores propostos por Carreiras (2006): a i) porcentagem da mulher no total da Força ativa; ii) restrições formais para funções de combate; iii) distribuição das mulheres militares em funções; iv) restrições formais de categorias; v) porcentagem de mulher na categoria de oficiais; vi) segregação em treinamento básico; vii) programas para a integração de gênero. As informações foram requeridas através 
de pedidos, realizados através FalaBr, que se destinaram aos três comandos das Forças Armadas e ao Ministério da Defesa. Os dados coletos foram inseridos em tabelas, gráficos e no corpo do texto, de modo a apresentar com clareza a distribuição e ocupação das mulheres militares nas Forças Armadas do Brasil.

A qualidade desse modelo está em se preocupar com variáveis que excedem valores absolutos, posto que não há somente indicadores que se atentam à porcentagem geral das mulheres na Força Ativa, mas há também aqueles que exploram os programas relativos à família das militares. Ao fim, será possível apresentar o atual estágio da incorporação tanto em termos quantitativos quanto qualitativos.

\section{Qual a representação da mulher militar no total da Força ativa?}

A primeira variável compreende apenas um indicador e este se refere à porcentagem da presença da mulher no total da Força ativa das Forças Armadas. Para tanto, é confirmado que, referente ao ano de 2020, a mulher equivale a 8,88\% desse pessoal. O que por um lado anuncia pouco acerca da maneira que as mulheres estão incorporadas, por outro é um ponto de partida para uma compreensão rápida e geral da presença da mulher dentro da estrutura militar, assim como fornece um dado suficiente para sucintas comparações entre diferentes Estados. Ainda que consideradobastante baixo e aquém de uma simetria ideal de 50\% homense $50 \%$ mulheres, a porcentagem da presença feminina na Força ativa é quase que o dobro daquela encontrada em 2009, quando estava em 4.89\%. Em números concretos, de 2009 para 2020 , as mulheres passaram de 16.758 para 31.791 integrantes.

Gráfico 1 - Evolução do efetivo militarfeminino(2009-2020)

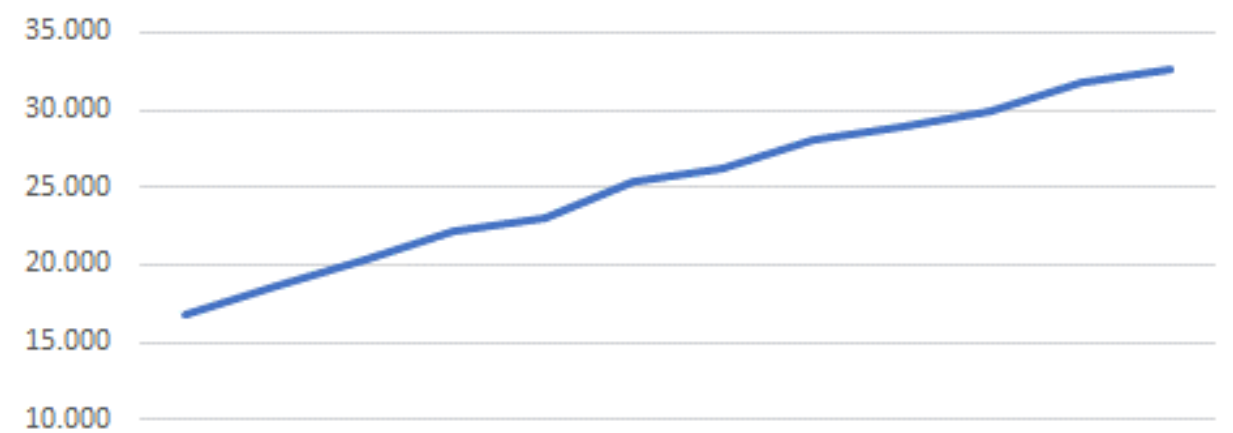

10.000

5.000

0

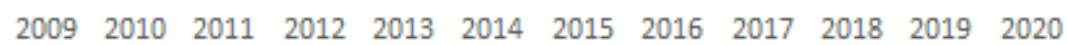

Fonte: Elaborado pelas autoras com dados do Ministério da Defesa, Secretaria-Geral - SG, Secretaria de Pessoal, Ensino, Saúde e Desporto - SEPESD e Departamento de Pessoal - DEPES e Divisão de Remuneração - DIREM. 2020.

Da porcentagem de mulheres que participaram da Instituição Militar em 2020, 3.30\% são representantes da Força Aérea, 2.32\% da Marinha e 3.26\% do Exército, isto é, o total de mulheres da Instituição Militar parece, inicialmente, estar em quantidades equilibradas dentro das três Forças. Todavia, à medida em que se aprecia a representação das mulheres dentro do total de integrantes da Força Aérea, da Marinha e do Exército, esse equilíbrio não mais se sustenta: elas representam 18.45\% da Força Aérea, 10.89\% da Marinha e, apenas, 5.36\% do Exército.

Sugere-se alguns potenciais motivos para essa desproporção. A primeira é o período em que o acesso de mulheres em cada uma dessas Forças foi autorizado. Sabe-se que, através da Lei no 6.807, foi a Marinha a pioneira em incorporar mulheres de forma permanente em seus quadros, quando esta criou o Corpo Auxiliar Feminino da Reserva da Marinha (CAFRM), em 1980. Um ano depois, em 1981, com a Lei no 6.924/81, houve a criação do Corpo Feminino da Reserva da Aeronáutica (CFRA), o qual constituiu o Quadro Feminino de Oficiais (QFO) e o Quadro Feminino de Graduadas (QFG) e teve sua primeira turma de mulheres ingressantes em 1982. A menor porcentagem de militares do sexo feminino no 
Exército, por sua vez, é potencialmente relacionada ao seu atardado período de aceitação das mulheres, oqual só ocorreu dez anos mais tarde, em 1992. Por meio do concurso público para a Escola de Administração do Exército (EsAEx), atualmente denominada de Escola de Formação Complementar (EsFCEx), as militares, asseguradas pela Lei n⿳0 7. 831, de 1989, ingressam no Exércitobrasileiro.

No entanto, caso esta primeira explicação fosse satisfatória, a Marinha contaria com uma mais alta porcentagem quando comparada a Aeronáutica e ao Exército, o que não se comprova porque a porcentagem feminina na Força Aérea é quase que $8 \%$ superior que da Marinha.

Para tanto, outra potencial explicação é inserida e associa-se aos fatores que vão além da permissão de acesso, como a entrada das mulheres nas Escolas de Formação de Oficiais. Na Academia da Força Aérea (AFA), este ocorreu em 1996 com o Aviso ministerial nº.006/GM3/024, de 1995, quando ainda não havia a obrigatoriedade por lei e nenhuma das outras duas Forças sequer cogitaram o assunto. A Marinha e o Exército, em contrapartida, aguardaram a aprovação da Lei $\mathrm{n}^{\circ} 12.705$, cujo artigo $7^{\circ}$ deu até o ano de 2017 para ambas as Forças permitirem oingresso de candidatas na linha de Ensino Bélico (BRASIL, 2012). A Escola Naval se antecipou um pouco e o fez em 2014. O exército, da sua parte, autorizou a formação de oficiais femininas no ano limite de 2017, na Escola Preparatória de Cadetes do Exército (EsPCEx). Assim, pode -se dizer que, em termos de formação acadêmica militar de mulheres que as possibilitasse atingir o generalato, a aeronáutica foi pioneira entre as três Forças, cumprindo um princípio constitucional da igualdade de gênero que até então não havia sido militarmente instituído. Outrossim, foi na Força Aérea que as mulheres ganharam, pela primeira vez, o acesso à atividade fim de uma Força, dado que se permitiu, em 2003, a participação feminina no Curso de Formação de Oficiais Aviadores (CFOAV). Em suma, a Aeronáutica, cedo quando comparada às outras Forças, agiu de forma mais aberta em relação ao acesso às mulheres militares.

\section{Em quais funções estão distribuídas as mulheres militares?}

Este indicador traz a divisão de cargos por gênero à análise. Julga-se que há, nas Forças Armadas, cargos que seguem padrões do gênero em razão de que cada ocupação não é proporcional à representação total de homens e mulheres em uma sociedade, sendo as mulheres sobretudo alocadas em funções tradições e fora do combate ${ }^{1}$.

Quando Carreiras (2006) reporta às funções tradicionais, estas são admitidas como aquelas que não têm encargos típicos de um combatente e tendem a se aproximar das civis por, principalmente, não assumir o aspecto físico como primordial para a consecução da função. Exatamente por essa razão, as funções tradicionais tendem a ser mais bem aceitas quando ocupadas por mulheres militares, sejam em cargos relativos à administração ou de planejamento e organização de pessoal. Da outra parte, as funções não tradicionais seriam aquelas próprias do ambiente de um combatente, como a pilotagem de aviões de guerra.

Para tanto, a distribuição não integrativa e desequilibrada dos militares homens e mulheres na Instituição Militar, segundo Carreiras (2006), expressa uma cultura de gênero desigual na qual a suposição que algumas tarefas são, por definição tácita, "inerentemente ou essencialmente de gênero" (CARREIRAS, 2006, p. 31, tradução nossa). A partir dos gráficos abaixo, aponta-se os quadros ocupados pelas mulheres.

\footnotetext{
Ainda que o Protocolo Adicional I da Convenção de Genebra considere todos os membros das Forças Armadas possíveis combatentes, toma-se aqui emprestado o conceito do Glossário das Forças Armadas do Brasil em que o militar não-combatente seria aquele que realiza serviços técnicos, administrativos e logísticos ao passo que os combatentes fazem parte da ação militar de objetivo restrito e limitado.
} 
Gráfico 2 - Distribuição de mulheres nos Corpos e Quadros da Marinha do Brasil (2020)

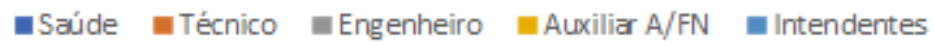

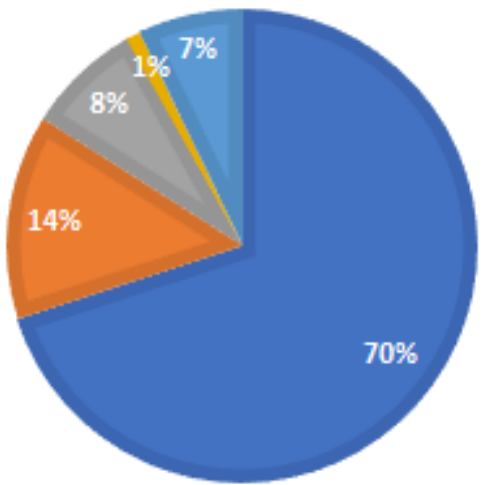

Fonte: Elaborado pelas autoras dos dados do IV Seminário Internacional da Escola Superior de Guerra (ESG) e do Centro de Estudos Hemisféricos de Defesa Willian J. Perry (WJPC), 2020.

Gráfico 3 - Distribuição de mulheres nos Corpos e Quadros do Exército do Brasil (2020) nQuadro Complementar Engenharia a Saúde

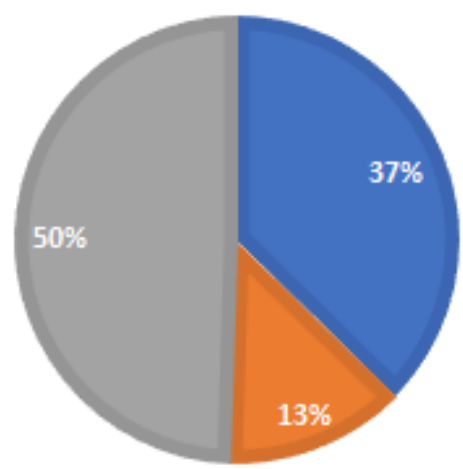

Fonte: Elaborado pelas autoras dos dados do IV Seminário Internacional da Escola Superior de Guerra (ESG) e do Centro de Estudos Hemisféricos de Defesa Willian J. Perry (WJPC), 2020.

Gráfico 4 - Distribuição de mulheres nos Corpose Quadros da Força Aérea do Brasil (2020)

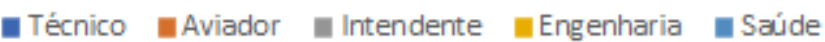

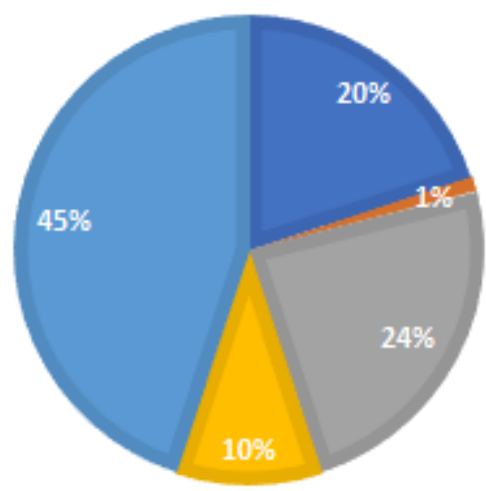

Fonte: Elaborado pelas autoras dos dados do IV Seminário Internacional da Escola Superior de Guerra (ESG) e do Centro de Estudos Hemisféricos de Defesa Willian J. Perry (WJPC), 2020. 
Em face do exposto, nota-se que os argumentos prós e contras realizados tanto na mídia brasileira como na própria Instituição Militar (DE ARAÚJO ALMEIDA, 2015) não parecem alterar a situação de discriminação crônica quando observado que, mesmo após 40 anos da entrada da mulher militarnas Forças Armadas do Brasil, ela ainda pouco participa das atividades de combate.

O tempo de ingresso explica, e parte, a concentração ocupacional do sexo feminino militar nasáreas tradicionais e a sub-representação nas áreas operacionais. É previsto que, à medida que a progressão de carreiras se efetue, integrantes passem a somar no quadro de combatentes. O corpo da Armada e de Fuzileiros Navais, por exemplo, passou a admitir mulheres apenas em 2019, fato que explica a inexistência de mulheres nesses quadros no período capturadoe indica que avanços ocorrerão em breve. Há, ademais, os obstáculos ao ace sso da mul her militar às funções de combatentes compõem uma divisão sexual do trabalho que existe há séculos, baseada em um modus operandi masculinizado, que a própria ONU visa desmantelar. Reunidos primeiramente na Resoluçãon ${ }^{0}$ 1325/2000, mas depois seguidos em várias outras resoluções que atualizam a matéria, os argumentos defendem que a igualdade entre homense mulheres nos cargos e funções militares não serve apenas para atender demandas feministas, mas é um auxiliar para a eficácia de uma operação militar inserida em um mundo de ameaças complexas. Todavia, as restriç̃̃es às posiç̃os de combate também esclarecem a condição. Enquanto há limitação às opções de combate e livre acesso aos postos tradicionais, é patente que os primeiros tenham menos representação feminina. Nesse sentido, seguimos ao exame dos obstáculos que travam a presença de mulheres militares na atividade fim da Instituição.

\section{As mulheres militares podem ser combatentes?}

\section{Marinha}

A Marinha do Brasil, embora tenha sido a Força pioneira ao abrir o acesso de mulheres à Instituição Militar, em 1980, mantinha restrito a participação das novas integrantes ao atendimento de encargos do interesse desta Força que estivessem relacionados com atividades técnicas e administrativas (BRASIL, 1987). Logo de início, portanto, configurou -se como total a restrição de mulheres às funções de combate que, no caso da Marinha, são representadas pelo Corpo da Armada e pelos Fuzileiros Navais.

Percorridos dezessete anos, a Lein ${ }^{0}$ 9.519, de 26 de novembro de 1997, promoveu uma reestruturação dos Corpos e Quadros de Oficiais e Praças da Marinha, a qual possibilitou que as Oficiais e Praças da Marinha passassem a prestar serviços no Corpo de Intendentes da Marinha (IM), no Corpo de Engenheiros da Marinha (EN), nos Quadros do Corpo de Saúde da Marinha, nos Quadros Técnico e Auxiliar da Armada do Corpo Auxiliar da Marinha, no Corpo Auxiliar de Praças e no Quadro de Músicos do Corpo de Praças de Fuzileiros Navais. Porém, ao prever que "serão ocupados por Oficiais do sexo masculino os cargos, respectivamente, do Corpo da Armada e do Corpo de Fuzileiros Navais” (BRASIL, 1997), as mulheres militares permaneciam distantes das atividades de combate e tampouco podiam atingir o posto máximo de Oficial General da Marinha cuja patente mais alta é a de Almirante.

A oportunidade, nesse sentido, efetuou-se apenas em 2017 quando, objetivando avançar no cumprimento da Lei no 12.705, sancionada em 2012 pela ex-presidente Dilma Rousseff, o Projeto de Lei da Câmara (PLC 147/2017) solicitou a liberação de acesso feminino a todos os cargos oficiais da sua Força, de modo que as mulheres pudessem ser admitidas em atividades de combate do Poder Naval. Diante da aprovação, sucedeu com a Lein ${ }^{\circ}$ 13.541, de 18/12/2017 uma nova redação do texto que se destinava aos direitos das mulheres da Marinha e, deste período em diante, estas passaram a integrar os Corpos da Armada e o de Fuzileiros Navais, até então restritos aos homens.

Ainda assim, o caminho é longo - levar-se-á em torno de 29 anos para que seja alcançado o primeiro posto de almirante. A despeito do tempo, todavia, não são mais encontradas restrições formais às posições de combate dentro da 
Marinha e, de maneira equitativa, a Escola Naval oferece às Aspirantes femininas as mesmas oportunidades de carreira que aos homens.

\section{Exército}

Dentro da linha bélica das Forças Armadas, o Exército foi o último a integrar a mulher militar. Embora aceitas desde 1992, a total restrição à categoria de combatentes impedia que as mulheres militares participassem dos quadros de combate que, no caso do Exército do Brasil, são constituídos pelas Armas (infantaria, cavalaria, artilharia, engenharia e comunicações), Quadro de Material Bélico e Serviço de Intendência.

Assim como no caso da Marinha, a mudança sóveio a ser realizada após a então Presidente Dilma sancionar, em 2012, a Lein ${ }^{0} 12.705$ cujo artigo $7^{\circ}$ autorizava as militares do sexo feminino a aturem como combatentes e, por conseguinte, atingirem a formação máxima de Oficial General. Anteriormente à assinatura da ex -presidente Dilma Rousseff, com base no determinado pelo Decreto ${ }^{\circ} 3.182$, de 23 de setembro de 1999, as mulheres só poderiam ser parte da área Científica e Tecnológica, de Saúde e Complementar (BRASIL, 1999).

De modo a cumprir o prazo de cinco anos para o ingresso de mulheres militares na linha bélica estabelecido pela Legislação, a Escola Preparatória de Cadetes do Exército (EsPCEx), em 2016, após ajustes em sua organização, passou a receber em 40 de suas 440 vagas as primeiras alunas. Após um ano de curso na EsPCEx, as alunas aprovadas seguem à Academia Militar das Agulhas Negras (AMAN), onde optam entre a especialização no serviço de Intendência ou no Quadro de Material Bélico. Portanto, referente ao de 2020, é possível que mulheres atuem na linha de combate e, após uma longa carreira militar, assumam um cargo de comando com três estrelas.

As restrições às funções de combate do Exército Brasileiro, todavia, permanecem. Os homens, os quais podem escolher entre os cursos de Infantaria, Cavalaria, Artilharia, Engenharia, Comunicações, Intendência e Material Bélico, ainda possuem oportunidades que não se aplicam às mulheres militares e, nesse sentido, são os únicos ocupantes das Armas. Outrossim, embora o Serviço de Intendência e Quadro de Material Bélico seja considerado pelo Comando do Exército como atividades de combatentes, as funções exercidas são de organização e logística - isto é, ainda que na linha bélica e consideradas combatentes, as mulheres militares ainda não pegam em armas.

\section{Força Aérea}

Dentre os variados quadros que compõem a Aeronáutica, os que efetivamente entram em combate sãoo Quadro de Infantaria e o Quadro de Aviação. Previamente à Marinha e ao Exército, a Força Aérea abriu o caminho feminino para o combate ainda em 2003, quando não aguardou a Lei12.705, de 2012 para permitir que as mulheres pudessemingressar na Aviação. Nesse período, mesmo que não participantes da Infantaria (o qual segue restrito aos homens militares), liberouse, com o Curso de Formação de Oficiais Aviadores, as portas para uma carreira quelevassem às militares do sexo feminino ao posto de Tenente-Brigadeiro, o mais alto na hierarquia da Aeronáutica.Assim, caso tenham sucesso nos rigorosos testes físicos, intelectuais e psicológicos, as pilotos de caça podem pertencer à elite combatente.

Segue abaixo sintéticos informes sobre as restrições formais de combate às mulheres na Marinha, Exércitoe Força Aérea. 
Tabela 1 - Restrições formais para a militar de sexo feminino para funções de combate

\begin{tabular}{|c|c|c|}
\hline FORÇA ARMADA & FUNÇÕES DE COMBATE & PERMISSÃO ÀS MULHERES \\
\hline \multirow{2}{*}{ Marinha } & Corpo da Armada & Sim \\
\hline & Quadro de Fuzileiros Navais & Sim \\
\hline \multirow{3}{*}{ Exército } & Armas (Infantaria, Artilharia, Cavalaria) & Não \\
\hline & Quadro de Material Bélico & Sim \\
\hline & Serviço de Intendência & Sim \\
\hline \multirow{2}{*}{ Força Aérea } & Quadro de Infantaria & Não \\
\hline & Quadro de Aviadores & Sim \\
\hline
\end{tabular}

Desporto - SEPESD e Departamento de Pessoal - DEPES e Divisão de Remuneração - DIREM, 2020.

Conforme apresentado, as mulheres são permitidas em cinco das sete opções de quadros de combate, isto é, há restrição formal de $28,5 \%$ das funções de combate. Como alegado até aqui, historicamente a mulher integra as áreas administrativas das Forças Armadas e, ainda que a partir de 2017 ocorra a incorporação da mulher militar na linha bélica dos três braços das Forças Armadas, as barreiras formais acabam por conservar a mulher em uma trajetória militar afastada do combate.

\section{Quais são as restrições formais de categorias para as mulheres militares?}

Com referência ao ano de 2020, não sãolocalizadas restrições formais de categorias, por gênero, dentro das Forças Armadas. Sendo assim, todas as Escolas Militares e Centros de Formação de Oficiais e Praças de carre ira ou temporários abrem o acesso para a participação de mulheres militares.

Todavia, cumpre notar que, malgrado a ausência de barreiras formais, são poucas as militares que alcançam os mais altos cargos nos postos e graduações das Forças Armadas e chegam a se tornar Oficiais-Generais. O motivo é que o caminho patente de ascender na carreira militar é através das Escolas de Formação de Oficiais, quais sejam, a Escola Naval, a Academia da Força Aérea e a Academia Militar das Agulhas Negras. Lembra-se, contudo, que as mulheres só passaram a frequentar tais Escolas em 1996, 2014 e 2018, respectivamente. Tomando em consideração que, após concluído o curso de formação, leva-se décadas de carreira para o Oficial ascender ao generalato, é notório a baixa ocupação feminina em patentes de quatro estrelas. A recurso de exemplo, apenas em 2050 será possível que as integrantes da Linha de Ensino Bélico concorram ao ingresso ao quadro de oficiais-generais.

Complementarmente, a persistente recusa de Quadros em autorizar a participação feminina militar, como o Quadro de Infantaria da Força Aérea ou o Quadro de Armas do Exército, faz com que haja redução das opções de caminhos para as funções hierarquicamente superiores dentro das Forças. Somado às reservas mais baixas de va gas para as mulheres quando comparadas àquelas disponíveis aos homens, novamente o resultadoé a maior dificuldade de se encontrar oficiaisgenerais do sexo feminino. No edital para ingresso em 2020, no Curso de Formação e Graduação de Oficiais de Carreira da Linha de Ensino Militar Bélico (CFO/LEMB), por exemplo, 400 vagas são destinadas aos homens, ao passo que 40 são atribuídas às mulheres. 
Outra explicação provém do tipo de serviço militar feminino que é efetivado dentro das Forças Armadas, istoé, se as militares são temporárias ou de carreira. No ano de 2020, o quantitativo de oficiais de carreira nas Forças Armadas estava em 5.032 e o quantitativo de oficiais temporários estava em 9.266. O ponto é que como cargos superiores exigem tempo, contratos de curto prazo ou o emprego como pessoal complementar impedem que muitas mulheres avancem na carreira.

Conjuntamente, ainda mais complexo é avaliar as restrições formais de categorias deixando de lado questões que ultrapassam o processo formal de progresso feminino na carreira militar. A trajetória das graduadas em ciências militares é envolvida pela superação e ocupação de espaços majoritariamente masculinos que, para além de boas relações sociais, demandam uma confiança capaz de gerar indicação para o cargo de general. Nesse sentido, é preciso se preocupar com a dinâmica de inclusão social enquanto requisito para profissões de comando e não apenas evoluções de carreira que são justificados unicamente pela competência. No mesmo ângulo, é provocativo notar que, essencialmente para o caso da mulher militar, outros fatores podem dificultar a permanência destas às suas funções na referida Instituição, posto que vários aspectos relacionados às condições econômicas globais, a participação das mulheres no mercado de trabalho, a conciliação do trabalho e da família e os valores relativos à igualdade de gênero ajudam a explicar as opções individuais.

Todavia, excedendo todas as adversidades, há mulheres posicionadas no Posto de Oficial-General de uma Força Armada. Mais especificamente, há duas: a Brigadeiro Carla Lyrio Martins, Oficial -General da FAB, e a Contra-Almirante Dalva Maria Carvalho Mendes, Oficial-General da Marinha. O Exército, por seu turno, ainda não conta com uma Oficial General entre eles. Em dados em 2020, constam nas Forças Armadas 226 homens generais e duas mulheres generais, ou seja, as mulheres representam 0,87\% do total. Em relação aos Coronéis e Capitães de Mar e Guerra, as mulheres são 4,97\% do total. Logo, ainda que sem restrição formal às patentes militares, os indicadores apontam para uma situação em que as mulheres ocupam cargos mais precários na estrutura militar e ainda estão longe de uma representação equitativa em cargos de poder dentro da Instituição.

\section{Qual é a presença da mulher militar nos postos e graduações das Forças Armadas?}

Em relação à presença da mulher nos postos e graduações das Forças Armadas, sabe-se que a maior fração integra a categoria de Oficiais (43,70\%). Segundo dados dos Comandos do Exército, Marinha e Força Aérea, há 14.298 Oficiais do sexo feminino na Instituição Militar do Brasil, de um total de 32.715 do efetivo feminino.

Acerca da distribuição de mulheres militares Oficiais entre as Forças, a variação é significativa: 42,05\% estão no Exército, 26,97\% na Marinha e 30,96\% na Força Aérea.

Tabela 2 - Quantitativo de Oficiais militares do sexo feminino, por Força.

\begin{tabular}{|l|l|}
\hline FORÇA ARMADA & OFICIAL MILITAR DO SEXO FEMININO \\
\hline Exército Brasileiro & 6013 \\
\hline Marinha do Brasil & 3857 \\
\hline Força Aérea Brasileira & 4.428 \\
\hline Total & 14298 \\
\hline
\end{tabular}

Fonte: Elaborado pelas autoras com dados do Ministério da Defesa, Secretaria-Geral - SG, Secretaria de Pessoal, Ensino, Saúde e Desporto - SEPESD e Departamento de Pessoal - DEPES e Divisão de Remuneração - DIREM, 2020. 
Não obstante, a concentração de mulheres oficiais em círculos e postos mantém um alinhamento: as categorias de $1^{\circ}$ e $2^{\circ}$ tenentes recebem o maior percentual feminino tanto no Exército (70\%), Marinha (57\%) e Força Aérea (76\%), na medida que o menor percentual feminino é encontrado no posto de Coronel, no Exército (0,63\%) e na Força Aérea (0,33\%), e no posto de Contra Almirante, no caso da Marinha (0,05\%). No Exército, não há mulheres nas categorias de Marechal, General do Exército, General da Divisão e General de Brigada. As categorias de Marechal do ar, Almirante -de-Esquadra e Vice-Almirante não são preenchidas na Marinha. E, na Força Aérea, os postos de Marechaldo Ar, Tenente Brigadeiro, Major Brigadeiro e Brigadeiro não são formados por militares do sexo feminino.

Tabela 3 - Quantitativo de Oficiais militares do sexo feminino, por posto e graduação

\begin{tabular}{|c|c|c|c|}
\hline \multirow[t]{2}{*}{ POSTOS E GRADUAÇÕES } & \multicolumn{3}{|c|}{ OFICIAL MILITAR DO SEXO FEMININO } \\
\hline & Marinha Brasileira & Exército Brasileiro & Força Aérea Brasileira \\
\hline Marechal Ar/Marechal / Alte & - & - & - \\
\hline Alte Esq/Gen Ex / Ten Brig Ar & - & - & - \\
\hline V Alte / Gen Div / Maj Brig & - & - & - \\
\hline C Alte / Gen Bda / Brig & 2 & - & - \\
\hline CMG / Ce & 82 & 38 & 15 \\
\hline CF / Ten Cel & 269 & 171 & 104 \\
\hline CC / Maj & 405 & 318 & 183 \\
\hline CT / Cap & 768 & 510 & 426 \\
\hline 10 tem & 1896 & 2287 & 2018 \\
\hline $2^{\circ}$ tem & 316 & 1934 & 1375 \\
\hline GM / Asp of & 119 & 755 & 307 \\
\hline
\end{tabular}

Quando em comparação entre os gêneros, repara-se que, apesar dos homens e mulheres oficiais estarem concentrados na categoria de Oficial Subalterno, a expressão dessa concentraçãoé bastante díspar: 76.98\% das mulheres oficiais formam a categoria de Oficial Subalterno, enquanto a porcentagem dos homens é de $51.00 \%$. 
Gráfico 5 - Distribuição, por posto, do efetivo femininoe masculino de Oficiais das Forças Armadas (2020)

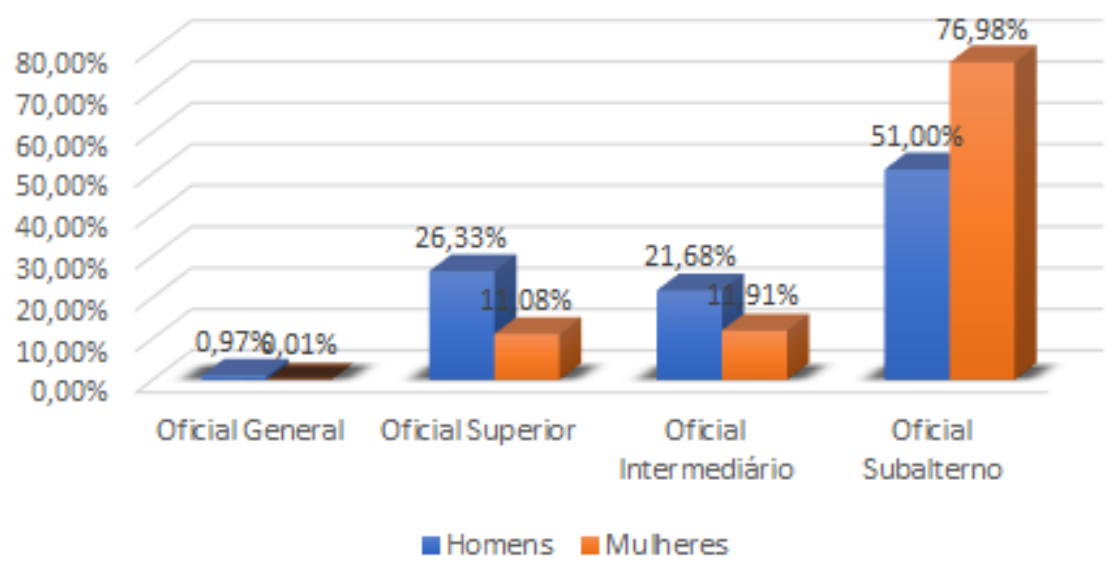

Fonte: Elaborado pelas autoras com dados do Ministério da Defesa, Secretaria-Geral - SG, Secretaria de Pessoal, Ensino, Saúde e Desporto - SEPESD e Departamento de Pessoal - DEPES e Divisão de Remuneração - DIREM, 2020.

Dessa forma, as informações testemunham que a maioria das mulheres nas Forças Armadas brasileiras são oficiais de escalão inferior. A principal razão para a baixa classificaçãoé que essas mulheres são frequentemente de corpos profissionais, servindo principalmente como médicas, advogadas, tradutoras, etc. (GIANNINI; LIMA; PEREIRA; 2016) e, por essa razão, suas progressões de carreira não chegam às altas patentes. Ademais, cabe destacar que as mulheres ocupam, em sua grande maioria, os postos temporários das carreiras, o que limita a sua atuaçãona atividade finalística das Forças, que éo combate.

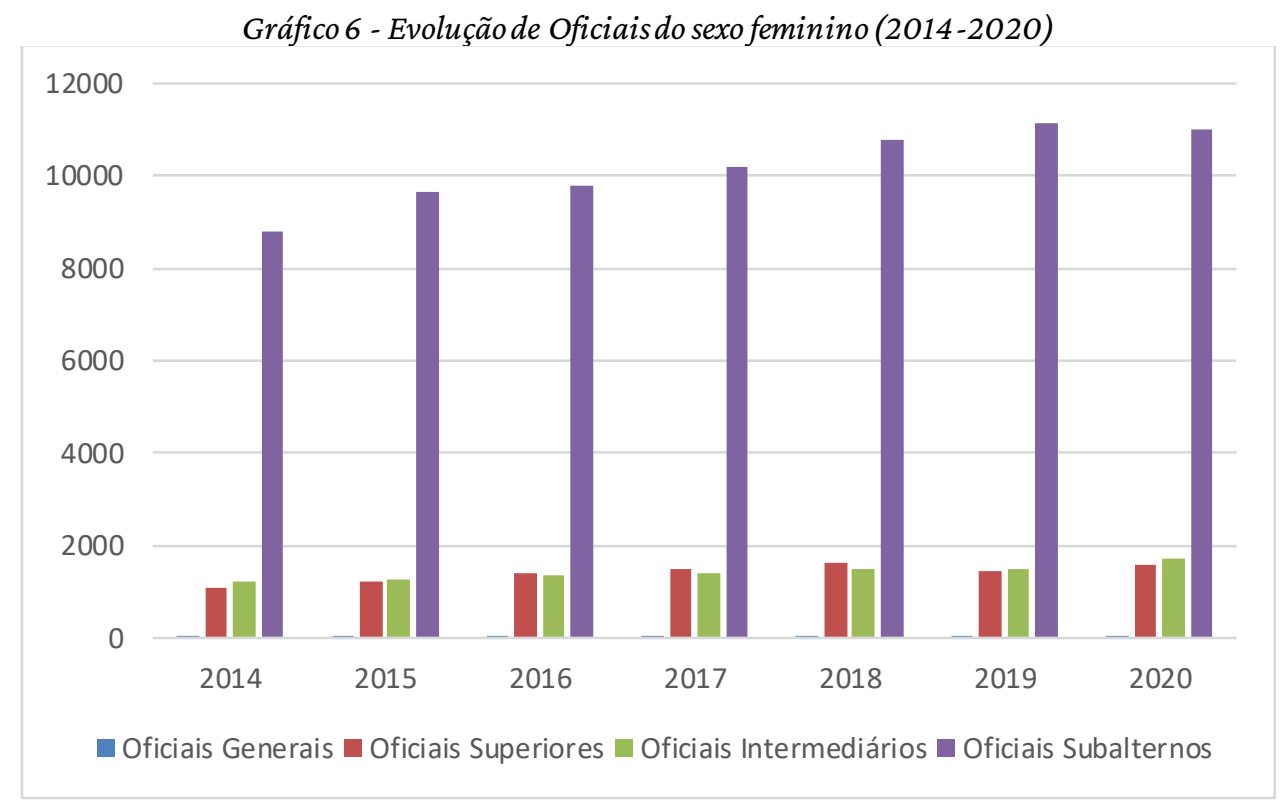

Fonte: Elaborado pelas autoras com dados do Ministério da Defesa, Secretaria-Geral - SG, Secretaria de Pessoal, Ensino, Saúde e Desporto - SEPESD e Departamento de Pessoal - DEPES e Divisão de Remuneração - DIREM, 2020.

Já em relação às posições de praças, graduados e cabos, estas representam $56.30 \%$ do total do efetivo feminino militar e estão concentradas na categoria de $3^{\circ}$ Sargento ( $55 \%$ do total feminino de Praças). Novamente, convém atentar que as mulheres não aparecem na totalidade dos Quadros e pouco se manifestam nas mais baixas patentes. 
Tabela 4 - Quantitativo de Praças militares do sexo feminino, por posto e graduação

\begin{tabular}{|c|c|c|c|}
\hline \multirow{2}{*}{ POSTOS E GRADUAÇÕES } & \multicolumn{3}{|c|}{ PRAÇA MILITAR DO SEXO FEMININO } \\
\hline & Marinha Brasileira & Exército Brasileiro & Força Aérea Brasileira \\
\hline Asp EN, Cad e Al IME (último ano) & 11 & 11 & 16 \\
\hline Asp EN, Cad e Al IME (demais anos) & 26 & 130 & 70 \\
\hline Al Órgão Form Of Res & 150 & - & 16 \\
\hline Al CN, EsPCEx e EPCAr (último ano) & - & 53 & 16 \\
\hline Al Es Form Sgt & 3 & 287 & 473 \\
\hline Al CN, EsPCEx e EPCAr (demais anos) & - & - & 39 \\
\hline Grumete & 13 & - & - \\
\hline Aprendiz-Marinheiro & - & - & - \\
\hline so / S Ten & 138 & - & 280 \\
\hline $1^{\circ} \mathrm{Sgt}$ & 238 & 21 & 871 \\
\hline $2^{\circ} \mathrm{Sgt}$ & 313 & 324 & 2650 \\
\hline $3^{\circ} \mathrm{Sgt}$ & 1746 & 5091 & 3309 \\
\hline Cb (engajado) & 2027 & 71 & - \\
\hline Cb (não engajado) & - & - & - \\
\hline TM & - & - & - \\
\hline T1 & - & - & - \\
\hline $\mathbf{T 2}$ & - & - & - \\
\hline MN, SD e S1 (especializado) & 11 & - & - \\
\hline MN, SD, S1 (não esp.) e S2 (engajado) & - & 3 & - \\
\hline MN-RC, SD-RC e S2 (não engajado) & - & 10 & - \\
\hline
\end{tabular}

Fonte: Elaborado pelas autoras com dados do Ministério da Defesa, Secretaria-Geral - SG, Secretaria de Pessoal, Ensino, Saúde e Desporto - SEPESD e Departamento de Pessoal - DEPES e Divisão de Remuneração-DIREM, 2020.

A informação de que 56,30\% das mulheres militares são Praças divulga pontos interessantes ao estudo. O primeiro é que, confrontado aos $88,43 \%$ dos homens que formam as Praças, a menor incidência feminina corrobora com a hipótese de que as mulheres são chamadas à caserna para exercerem atividades técnicas inseridas tanto na lógica de mercado como 
o sistema patriarcal: o número de mulheres na categoria de cabos, soldados e marinheiros é irrisório porque tanto tais funções requerem menor nível de estudo e pagam menor salário como representam atividades masculinizadas (isto é, com o maior uso da força) por serem típicas de um combatente. Como uma segunda observação está o fato de que a inconsistência de mulheres nesses cargos mencionados - típicas de um soldado porque representam atividades masculinizadas -, elaboram uma setorização quanto à presença feminina na Instituição Militar e corroboram em desassociar a mulher da imagem do guerreiro em um conflito. Por último, o terceiro ponto explica que, em razão de tal distribuição, cria-se um cenário bastante particular onde o rendimento médio de mulheres militares é superior ao dos homens. Segundo o Atlas do Estado Brasileiro, é na categoria dos militares federais a única situação em que se registra uma remuneração mensal média de mulheres superior à dos homens (IPEA, 2019) por um motivo simples: há 6.5\% de mulheres exercendo a função de cabos ao mesmo tempo em que há $58.04 \%$ de homens na mesma ocupação. À luz do exposto, situam-se as mulheres militares em 23 dos 30 dos possíveis postos e graduações das Forças do Brasil, o que configura um preenchimento de $76,66 \%$.

\section{Há segregação no treinamento básico entre homens e mulheres militares?}

A Academia Militar é o espaço que prepara o combatente para a guerra e, por conta disso, as tarefas que demandam o desempenho de alta carga física são definidas por padrões que datam a inauguração desses espaços. Sucede, no entanto, que tais treinamentos se amparam em um único tipo biológico (o masculino), o que causa desconformidade com as militares mulheres que passam a integrar as Forças Armadas. Pois, a adequabilidade do treinamento físico militar (TFM) e sua respectiva avaliação foram requisitadas a partir da década de 1990, de forma a permitir a evolução física desse novo segmento pudessem responder às demandas das peculiares atividades da carreira militar. Em relação à linha bélica do Exército brasileiro, o Instituto de Pesquisa da Capacitação Física do Exército (IPCFEx) passou a conduzir estudos de modo a acompanhar o desempenho de alunas do sexo feminino, sugerir estratégias de TFM voltadas para as demandas identificadas e, por fim, manter atualizado o processo de avaliação do TFM de forma justa e proporcional.ao biotipo de cada sexo.

Todavia, salienta-se que, com a exceção de ajustes compensatórios nos testes de avaliação física, a ouvidoria do Exército confirma que não existe qualquer segregação entre militares do segmento feminino ou masculino, sendo as previstas atividades de instrução realizadas de forma integrada dentro da fração considerada. Além disso, as alunas prestam o mesmo concurso (composto por prova intelectual, avaliação de saúde e avaliação física) e realizam os mesmos cursos e as mesmas competências técnico-profissionais que são inerentes a formação do oficial combatente, sem distinção de sexo. Inclusive, não há um pelotão exclusivo de mulheres e elas recebem a mesma educação militar; a única diferença entre homens e mulheres, portanto, são os índices de aprovação no treinamento físico militar, que é distinto conforme o sexo.

Quando questionado ao Comando da Marinha sobre possíveis segregações, este declarou, através do Falabr, que “a única diferenciação entre homens e mulheres na Marinha, diz respeito ao Teste de Aptidão Física, que é obrigatório nos cursos de formação, quanto na manutenção da carreira”. Por sua vez, a Aeronáutica informou que "os treinamentos físicos no âmbito da Aeronáutica são executados ao mesmo tempo entre o efetivo masculino e feminino, no entanto, o grau de exigência para aprovação nos Testes de Avaliação de Condicionamento Físico é diferenciado de acordo com o sexo dos avaliados”.

\section{Há programas para a integração de gênero nas Forças Armadas?}

O último indicativo recai sobre as políticas sociais direcionadas às mulheres militares e solicita a presença ou ausência de diretrizes que buscam melhorar, de maneira ordenada, a qualidade da presença feminina nas Forças Armadas. 
As medidas em vista, para além de ações emergenciais e de curto prazo, são apreciadas como "políticas atentas a integração qualitativa das mulheres no ambiente militar que aqui serão compreendidas como as políticas de gênero; istoé, aquelas políticas que asseguram direitos e findam com a desigualdade e a discriminação”, como explica Schwether (2020). Neste estudo, analisar-se-á três aspectos: os programas familiares, os planos de integração militar feminina, e como é realizado o monitoramento de assédio.

Acerca do primeiro aspecto, esclarece-se que a investigação dos programas familiares, é fundamental porque a conciliação entre a carreira e a família é uma das barreiras à permanência feminina em postos militares (HUFFMAN; CULBERTSON; BARBOUR, 2015; KING; DINITTO, 2019) e, por conseguinte, mudanças nessas políticas podem influenciar positivamente a retenção militar feminina (SEGAL,1986).

Ainda assim, para o caso do Brasil de 2020, é dado que tais programas não se fazem presentes no setor militar do país (SCHWETHER, 2020). Observado o caso das Forças Armadas, não são encontrados programas específicos pretendam progressos expressivos no que concerne ao relacionamento familiar das militares, estando apenas o cumprimento da lei civil como as ações identificadas. Os avanços no trato das mulheres no meio militar, os quais tiveram origem sobretudo durante a presidência de Dilma Rousseff (2011-2016), têm como exemplo a eliminação da restrição à participação de mulheres grávidas na seleção dos postos da Marinha e a aprovação da Lei no 13.109, de 2015, a qual garante licença à gestante e à adotante. Sem embargo, recoloca-se que tais benefícios, já concedidos às servidoras públicas civis, são ações que, embora necessárias, não formam um caminholinear de objetivos deliberados às famílias das mulheres militares que, pela singularidade da função, requerem políticas particulares.

Acerca dos planos que objetivem a incorporação feminina militar nas Forças Armadas do Brasil, sua presença não é constatada. O que é encontrado, em mais próximo conteúdo, sãoplanos e ações de Ministérios (inclusive o Ministério da Defesa) que visam avançar na solução de problemas relativos à segurança da mulher e, por conseguinte, tangenciam o tema da mulher militar.

Como exemplo a ser citado, verifica-se que, quando criado o Plano Nacional de Políticas para as Mulheres (PNPM), as suas duas primeiras edições (2005 e 2008) sequer contemplaram os termos "mulher militar" ou "Forças Armadas”. Somente no terceiro PNPM, destinado aos anos de 2013 a 2015, passou-se a mencionar políticas referenciando mulheres militares em uma de suas Linhas de Ação. No caso, o objetivo 4.3 incidiu sobre o fortalecimento da segurança cidadã e acesso à justiça para mulheres em situação de violência e, por esta razão, associa -se às atribuições e capacitações das mulheres nas Tropas de Paz, ao fortalecimento da segurança cidadã e acesso à justiça para mulheres em situação de violência e, por esta razão, associou -se às atribuições e capacitações das mulheres nas Tropas de Paz, ao fortalecimento de práticas esportivas como instrumento de paz nos locais de atuação das Forças Armadas, às questões acerca d a prevenção de doenças em teatros de guerras e, por fim, ao enfrentamento da violência sexual como arma em contextos de guerra e humanitários. Ainda assim, não se reconhece que este Plano formou um programa coeso que teve como anseio progressos na integração da mulher militar nas Forças Armadas do Brasil.

Uma outra evidência da ausência de políticas específicas para a integração de gênero nas Forças Armadas pode ser percebida através da Comissão de Gênero (CGMD) que, através da Portaria No 893/MD e sob a re sponsabilidade do Ministério da Defesa, formou-se, em 2014, com caráter consultivo. Todavia, embora ambiciosa, a Comissão careceu de um cronograma para execução das ações, assim como falhou em estabelecer um orçamento, as fontes de financiamento e os indicadores que possibilitem a avaliação dos resultados. Ainda que formada tanto por civis quanto por militares do Ministério da Defesa e Forças Armadas (SCHWETHER, 2016), os objetivos foram frágeis e não consistentes enquanto proposta que assegurasse direitos e a não discriminação da mulher militar.

Ademais, recorda-se que a Portaria no 529/GM/MS, de 2013, institui o Projeto Inserção do Sexo Feminino sob a supervisão do Estado-Maior do Exército (EME) e, à princípio, teve boas intenções. É, sim, tido que as medidas administrativas buscaram adaptações e revisões de regulamentos e normas, de modo a dar melhores condições às 
operações de cadetes homens e mulheres. (DECEX, 2018). Outrossim, mais recentemente, o Ministério da Defesa, por intermédio da CGMD e com a colaboração do Ministério das Relações Exteriores e Ministério da Justiça e Cidadania, aprovou o Plano Nacional de Ação sobre Mulheres, Paz e Segurança (PNA, 2017), o qual assegurou o compromisso do Estado brasileiro em cumprir a Resolução no 1325/2000 da ONU. Não obstante, ambos os eventos seguiram a lógica antes destacada como fora do escopo principal da integração de gênero entre os militares e, para tanto, inserem-se também como projetos e planos acessórios que, em contraste com o solicitado pelo indicador, não se dispõem em monitorar a qualidade da incorporação feminina nas Forças Armadas.

Especificadamente sobre o assédio sexual nas Forças Armadas, as posições também são reativas ao cumprimento da lei geral e dos regulamentos disciplinares militares, sem a ocorrência de políticas específicas. O próprio Código Penal Militar (CPM) não prevê o crime de assédio sexual porque, enquanto na sua elaboração, as mulheres não participavam, ainda, das Instituições Militares. Mesmo no Ministério da Defesa, após consulta ao Falabr, a administração central deste Ministério afirma que não existem documentos relativos à realização de políticas públicasvoltadas ao combate ao assédio moral e sexual noâmbito da Pasta.

As ações que tangenciam o campo do assédio sexual fazem parte de normas de conduta mais amplas destinadas a lidar com a discriminação, como aquelas que consistem em valorizar a ética militar, o respeito ao próximo, a "honra pessoal” e o "decoro da classe”. Segundo o Comando da Marinha em resposta às ações de m onitoramento de assédio sexual solicitadas pelo Acesso à Informação, consta que "as Escolas militares instruem seus alunos a terem uma conduta ética e observadora das normas vigentes no nosso país, direcionada, sempre, a um comportamento correto, lícito e ilibado”. Para tanto, a abordagem para questões de assédio e discriminação de gênero não estão integrados em nenhum programa mais amplo ou mesmo dentro de uma política explícita.

Configurado o assédio, o que ocorre é que a conduta do militar é punida com o crime definido pelo art. 216-A do Código Penal (CP). Há a ocorrência de uma sindicância e todos os trâmites judiciais legais são realizados, a fim de que sejam tomadas as providências pertinentes e o ato não fique impune perante não só por ir ao código -jurídico mas também por contradizer preceitos éticos e ao pundonor militar. Estas medidas, no entanto, são mais reativas do que pensadas propriamente dentro de uma política de prevenção ao assédio sexual.

\section{A mulher militar está integrada às Forças Armadas do Brasil?}

Este artigo, com a intenção de realizar uma apreciação do estágio no qual se encontra a incorporação da mulher militar no Brasil na segunda década dos anos 2000, analisou sete indicadores. O primeiro, o qual pretendia a obtenção do número de mulheres militares no total da Força ativa, revelou a discrepância da presença de homens e mulheres nas Forças Armadas do Brasil, sendo a porcentagem, respectivamente, de 8,88\% e 91,12\%. Com o segundo parâmetro, buscou -se investigar como as mulheres militares estão distribuídas nas Forças Armadas e constatou-se que elas sobretudo ocupam cargos técnicos e de saúde. O terceiro, procurou saber se é permitidoàs mulheres que participam da Instituição Militar do país a ocupação do cargo de combate e compreendeu-se que estas podem pegar em armas, mas de maneira limitada. Entendeu-se, com o quarto indicador, que as militares do sexo feminino são autorizadas a participar de todos os postos das Forças Armadas, ainda que não o façam em razão do tempo necessário para progressão na carreira, da ausência de políticas de incentivo e da menor oferta de vagas nas Academias Militares. O quinto dedicou -se a demonstrar que as mulheres não constam nos postos e graduações das Forças Armadas de maneira equilibrada, já que estão concen tradas em quadros técnicos que as distanciam tanto da categoria de Oficiais-Generais como da categoria de cabos e soldados. Enquanto indicador que revela uma situação equitativa entre os gêneros, no entanto, apresentou estar o treinamento físico, posto que este não distingue o sexo na definição das atividades. Por fim, o indicador sete evidenciou a ausência de políticas sociais que pleiteiam atenuar as desigualdades entre os gêneros aqui expostas. 
Da avaliação empreendida, conclui-se que a presença da mulhermilitar nas Forças Armadas, em 2020, é bastante inferior à participação masculina; na prática, o acessoé regularmente obstruído por uma menor oferta de vagas e políticas que visem alterar essa dinâmica. O resultado é que essa baixa presença militar feminina indica um envolvimento conflituoso entre o setor civil e o setor militar porque o gêneroé um aspecto que pressupõe uma harmônica relação entre civis e militares de um Estado, uma vez que demonstra se os valores da sociedade estão ou não representados nas Forças.

É por isso que, ao fim, a Resolução $1325 / 2000$ da ONU e os estudos que tratam do tema da mulher militar expandem a ideia de que os valores sociais democráticos podem ser mais bem alcançados em um cenário onde as questões do gênero nas Forças Armadas são abordadas e refletidas como o respeito aos princípios de igualdade de oportunidades e cidadania de toda uma sociedade. Nesse sentido, a não integração de mulheres e perspectivas de gênero nas Forças Armadas deixa de criar oportunidades para revisar conceitos culturais e modelos organizacionais, adaptando a estrutura militar para maximizar sua eficácia.

Por fim, entende-se que há um desequilíbrio nas relações civis-militares do Brasil porque as Forças Armadas não respondem simultaneamente a demanda da eficácia militar em meio a um contexto estratégico e a indispensabilidade de assegurar os valores sociais daqueles que os comandam (PENIDO; MATHIAS, 2019).

\section{Referências}

DE ARAÚJO ALMEIDA, Vítor Hugo. Mulheres nas Forças Armadas Brasileiras: situação atual e perspectivas futuras. Estudo para Consultoria Legislativa, 2015.

BRASIL. PRESIDÊNCIA DA REPÚBLICA. (Ed.). LEI N 6.622, DE 09 DE JUNHO DE 1987: Casa Civil Subchefia para Assuntos Jurídicos. 1987.

BRASIL. PRESIDÊNCIA DA REPÚBLICA. (Ed.). LEI No 12.705, DE 8 DE AGOSTO DE 2012: Casa Civil Subchefia para Assuntos Jurídicos. 2012.

BURK, James. Theories of democratic civil-military relations. Armed Forces \& Society, v. 29, n. 1, p. 7-29, 2002.

CARREIRAS, Helena. Gender and the military: Women in the armed forces of western democracies. Routledge, 2006.

CARREIRAS, Helena. Gender and civil-military relations. Gender and civil-military relations, n. 1, p. 1-18,2015.

GIANNINI, Renata; LIMA, Mariana; PEREIRA, Pérola. Brazil and UN Security Council Resolution 1325. Prism, v. 6, n. 1, p. 178 -197, 2016.

HUFFMAN, Ann H.; CULBERTSON, Satoris S.; BARBOUR, Joseph. Gender roles in a masculine occupation: Military men and women's differential negotiation of the work-family interface. In: Gender and the work-family experience. Springer, Cham, 2015. p. 271-289.

KING, Erika Lee; DINITTO, Diana M. Historical policies affecting women's military and family roles. International Journal of Sociology and Social Policy, 2019.

MATHIAS, Suzeley; ADÃO, M. Mulheres e vida militar. Cadernos Adenauer, v. 14, n. 3, p. 145-165, 2013.

MOORE, Brenda L. Introduction to Armed Forces \& Society: Special issue on women in the military. 2017.

PENIDO, Ana; MATHIAS, Suzeley Kalil. Profissionalizar, um verbo transitivo. Perseu: História, Memória e Política, n. 18, 2019.

SCHWETHER, Natália Diniz et al. AGORA É QUE SÃO ELAS: Desvendando o processo de incorporação das mulheres nas Forças Armadas de Brasil e Argentina. 2016.

SCHWETHER, Natália. SOBRE GÊNERO: uma Análise Qualitativa Comparada das Políticas de Defesa dos países SulAmericanos. REVISTA BRASILEIRA DE ESTUDOS ESTRATÉGICOS, v. 12, n. 23, 2020.

SEGAL, Mady Wechsler. The military and the family as greedy institutions. Armed forces \& society, v. 13, n. 1, p. 9-38,1986.

\begin{tabular}{ll}
\hline Funções de colaboração exercidas & \\
\hline Isabella Neumamn: & Curadoria de dados; Análise formal; Investigação; Escrita (primeira redação); Escrita (revisão eedição); \\
Graciela de Conti Pagliari: & Validação; Supervisão; \\
\hline
\end{tabular}

